\title{
The adverse drug reactions to tumor necrosis factor alpha inhibitor
}

\author{
Hye-Kyung Park ${ }^{*}$, Eun-Jung Jo ${ }^{1}$, Seung-Eun Lee ${ }^{2}$, Jung-Ha Mok', Mi-Hyun Kim', Kwangha Lee ${ }^{1}$, Ki-Uk Kim, \\ Min-Ki Lee ${ }^{1}$
}

From 6th Drug Hypersensitivity Meeting (DHM 6)

Bern, Switzerland. 9-12 April 2014

\section{Background}

Biologic therapies targeting tumor necrosis factor alpha (TNFa) are a mainstay in the treatment of autoimmune diseases such as ankylosing spondylitis (AS), rheumatoid arthritis (RA), or Crohn's disease (CD). With increased use of the biologic therapies, various adverse effects to TNFa inhibitor have been reported.

\section{Method}

We reviewed retrospectively the clinical data of subject who were treated with infliximab, adalimumab, or etanercept from 2006 to 2012, and assessed the adverse drug reactions using electronic medical recording system in Pusan National University Hospital.

\section{Results}

In total, 111 subjects were enrolled. Mean age was $39.8 \mathrm{i}^{3} / 411.7$ years, and male was $68.5 \%$. The diagnoses of subjects were AS (62.2\%), RA (24\%), CD (17\%), and pyoderma gangrenosum $(0.9 \%)$. The injected agents were adalimumab (53.2\%), etanercept (29\%), and infliximab (20.7\%). Adverse drug reactions of $30.6 \%$ were reported. The most common adverse reactions were cutaneous reactions; 10 (9.0\%) eczema, $4(3.6 \%)$ injection site reaction, and $2(1.8 \%)$ urticaria. $3.6 \%$ of subjects had a slight increase in liver enzyme, and pulmonary tuberculosis occurred in $2(1.8 \%)$ patients. Mean therapy duration prior to adverse reactions was $2.1 i^{3 / 4} 2.2$ years. Serious adverse reaction, anaphylaxis, growth retardation, and Henoch-Schönlein purpura occurred in one patient each.

\section{Conclusion}

This study shows that the adverse reactions to TNFa inhibitors were frequent, but most of them were mild reactions and the most common adverse reaction was cutaneous reactions.

\section{Acknowledgment}

This research was supported by a grant from Ministry of Food and Drug Safety to operation of the regional pharmacovigilance center in 2014

\section{Authors' details}

'Pusan National University School of Medicine, Department of Internal Medicine, Korea, Republic of. ${ }^{2}$ Pusan National University Yangsan Hospital, Department of Internal Medicine, Korea, Republic of.

Published: 18 July 2014

doi:10.1186/2045-7022-4-S3-P53

Cite this article as: Park et al:: The adverse drug reactions to tumor necrosis factor alpha inhibitor. Clinical and Translational Allergy 2014 4(Suppl 3):P53.

Submit your next manuscript to BioMed Central and take full advantage of:

- Convenient online submission

- Thorough peer review

- No space constraints or color figure charges

- Immediate publication on acceptance

- Inclusion in PubMed, CAS, Scopus and Google Scholar

- Research which is freely available for redistribution

Submit your manuscript at www.biomedcentral.com/submit
( Biomed Central

Pusan National University School of Medicine, Department of Internal Medicine, Korea, Republic of

Full list of author information is available at the end of the article 